\title{
Working Memory Scale
}

National Cancer Institute

\section{Source}

National Cancer Institute. Working Memory Scale. NCI Thesaurus. Code C121468.

A rating scale included in the Behavior Rating Inventory of Executive Function that measures the ability of an individual to hold information when completing a task, encoding information, or generating goals and plans in a sequential manner. 